Research Article

\title{
Effect of Used Motor Oil and Bitumen as Additive on the Permeability and Mechanical Properties of Low Plastic Soil
}

\author{
Kamran Iqbal $\mathbb{D},{ }^{1}$ Chengshun Xu, ${ }^{1}$ Hassan Nasir $\left(\mathbb{D},{ }^{2}\right.$ Muhammad Alam $(D), 3$ \\ Asim Farooq $\mathbb{D}^{2}{ }^{2}$ and Edward J. Williams ${ }^{4}$ \\ ${ }^{1}$ Department of Civil Engineering, Beijing University of Technology, Beijing, China \\ ${ }^{2}$ Department of Civil Engineering, CECOS University of IT and Emerging Sciences, Peshawar, Pakistan \\ ${ }^{3}$ Department of Civil Engineering, Abasyn University, Peshawar, Pakistan \\ ${ }^{4}$ Department of Civil Engineering, University of Michigan-Dearborn, Dearborn, Michigan, USA
}

Correspondence should be addressed to Kamran Iqbal; kamran@emails.bjut.edu.cn

Received 16 April 2020; Accepted 8 July 2020; Published 30 July 2020

Guest Editor: Zhen Leng

Copyright ( 2020 Kamran Iqbal et al. This is an open access article distributed under the Creative Commons Attribution License, which permits unrestricted use, distribution, and reproduction in any medium, provided the original work is properly cited.

Stability of permeable soils near large-scale water reservoirs for paved and unpaved road pavements is all too frequently compromised due to excessive seepage and the climatic conditions of that area. In this research, a multilevel research approach was adopted by conducting a comparative study of the microspectroscopy through Fourier transform infrared (FTIR) spectra to investigate the maximum absorbance correlation along with mechanical investigations (such as the compressive strength, modified proctor test, California bearing ratio test, and swell percentage test). The native low plastic soil sample (CL) was blended with varying percentages of petroleum additives (bitumen and used motor oil) independently at $0 \%, 4 \%, 8 \%, 12 \%, 16 \%$, and $20 \%$. A comparison of results in the case of bitumen and used motor oil revealed that a decrease in Atterberg's limits occurred accompanied by an increase of bitumen blending percentage, while used motor oil (UMO) increased the plastic limit. Maximum dry density (MDD) increases while optimum moisture content (OMC) decreases with the increase in bitumen. Used motor oil (UMO) initially (up to 4\%) increased the MDD and subsequently decreased it. Investigative reports show that bitumen causes a decrease in swell percentage and increases California bearing ratio (CBR), whereas UMO causes a continuous increase in percentage swell and decrease in CBR. The addition of bitumen in soil resulted in a decrease in the coefficient of permeability $(k)$, while UMO has a significant result of up to $4 \%$. Regarding the control sample, spectrum analysis through FTIR effectively supports the laboratory results as the intensity of peaks increases with the oil, and bitumen concentration reveals that oil and bitumen impart cementitious property to the soil. Moreover, this research work by experiment supported and strengthened the idea of soil pavement stabilization through bitumen, which gives antiwater stability, and facilitates low-cost construction by obtaining raw material on the spot. UMO adversely affects soil properties beyond $4 \%$ addition by weight.

\section{Introduction}

Considering the material quality, plus transport, economic, and political issues, engineers sometimes must use lowquality soil during road construction. These low-quality soil materials are prone to show unattractive engineering behavior, such as low bearing capacity, susceptibility to differential settlement, high percentage swell, high moisture susceptibility, and poor permeability or seepage behavior. This type of unwanted soil behavior is generally attributed to the nature of the soil and the fine-grained components present in the soil material. Thus, fine-grained soils such as silts and clays proved to be the most problematic materials [1]. Stabilizing such type of local material has millions of years of history [2]. This research attempted to improve certain desired geotechnical properties such as shear strength parameters $(c-\phi)$, permeability, $\mathrm{CBR}$, and the compaction behavior of locally available soil of Peshawar, Pakistan, through used motor oil (UMO) and bitumen.

UMO, also known as waste crankcase oil or waste engine oil, is a lubricating oil used in the crankcase of an internal combustion engine [3]. This UMO is a mixture of $90 \%$ 
hydrocarbons and some other metals such as sulphur, chlorine, and magnesium for about $10 \%$. It cannot be easily differentiated in chemical components other than to say that the major part is either aliphatic or aromatic hydrocarbons $[4,5]$. After use, it loses its original desired properties due to the breakdown of the additives during the combustion process. It is considered as the main source of environmental pollution if contaminated or burnt in the air because it contains a high level of heavy metals [6]. Pakistan produces 11246 tons of UMO annually. If most of the quantity does not recycle, it will pollute the environment because the waste recycling concept and circular economy is a positive approach to analyse economic, social, and environmental impacts [7]. In this present research, impacts of waste UMO have been studied to reuse in the stabilization of low plastic soil. Many methods of soil stabilization with oil have been proposed by different researchers. Researchers such as Evgin et al., Khamehchiyan et al., and Ukpong et al. studied the changing behavior of soil by considering the effects of crude oil [8-10]. Rasheed et al. demonstrate that the PL and LL increase, while MDD and OMC decrease with the increase in oil percentage as an additive in soil [11]. The behavior of motor oil on cohesion and CBR was studied by Nazir who stated that cohesion decreases while the angle of internal friction $\phi$ increases with an increase in the tendency of motor oil in soil [12].

Bitumen, a by-product of crude petroleum, had also been used for soil stabilization for a very long time in the form of cutback, emulsified, and foamed bitumen [13]. Bitumen, when mixed with soil, helps in binding of the soil particles thereby increasing the cohesive strength of the soil [14]. Nicholson stated that bitumen and its products are mostly used in the soil as an additive, to provide water repulsion and/or adding cohesive strength to the soil [15]. Grouting with hot bitumen for the remedial measure was first introduced in the end of the $19^{\text {th }}$ century [16]. Dr. Erich Schonian is one of those scientists who wrote first about the behavior of hot bitumen's penetration in cracks and voids [17]. Bituminous substances are used to stabilize the soil, particularly for stabilizing subgrade, subbase, or even base course of road carrying higher traffic load [18]. This research paper expostulated upon hot bitumen in soil stabilization for the stability of road embankment.

Bitumen is a viscous elastic material mostly produced by the crude oil distillation process. It is frequently used in the asphalt pavement with some other civil works such as waterproofing, insulating material, tank material, and flooring material. Bitumen, if mixed in soil, will affect its geotechnical properties [19]. Nasr, in his research, investigates the behavior of strip footing on bitumen-contaminated sand $(0-5 \%)$ by weight [20]. Michael studied contaminants in the soil stabilization process in soil stabilization using emulsified bitumen following bench-scale evaluation [21]. Vishal Kumar uses emulsified bitumen with a small amount of cement, for gravel road soil stabilization by considering CBR as a key factor in his experimental work [22].

Research on low plastic soil shows that the Phi " $\phi$ " angle of internal friction increases while cohesion " $C$ " decreases when the oil content increases [14]. Initially, soils had been stabilized by cement and lime, but this trend was changed by the innovation known as foamed bitumen stabilization [23]. Paul and Gnanendran suggest that soil stabilization as an aggregate and bitumen mixture could make a waterproof layer in sublayers of a road embankment [24]. Jones et al. follow indirect tensile stabilization for experimental work on cement-bitumen showing that soil achieves early strength, thereby allowing traffic in the curing stage [25].

Dr. Arora explained that bitumen are hydrocarbons, readily soluble in carbon disulphide $\left(\mathrm{CS}_{2}\right)$ and are obtained from refined petroleum products. It can be used as a cutback, emulsified, and even directly. Any inorganic soil can be stabilized through bitumen. It makes soil waterproof by plugging its voids and helps cohesive soil in lower moisture content and higher bearing capacity [26].

This research has the potential to minimize the failures of local road and highways in Pakistan by imparting strength and stability to the poor material used in the road construction and reduce the water seepage effect, both of which cause serious damage to the roads. This research will help to investigate the geotechnical properties and internal chemical spectroscopy (Atterberg's limits, compaction test, shear strength parameters, CBR, permeability, and FTIR) of low plastic soil with the hope of stabilization with UMO and bitumen. Stabilization of the native soil has been seriously felt acutely because of the premature failure of the local roads due to population growth, environmental factors, and minimum resources that collectively lead to huge economic and environmental losses to the country.

\section{Materials and Methods}

Figure 1 shows work scheme followed in this research work from soil collection, stabilization with bitumen, and UMO to independent investigation for the expected change in geotechnical properties. Continuous and gentle mixing was applied for both the liquid additives to ensure proper mixing. At room temperature, the mixing of bitumen with soil is quite difficult, so bitumen was heated to a temperature of $140^{\circ} \mathrm{C}$ with constant stirring. Then the dry soil was weighed, and the required $\%$ of bitumen was added and mixed at $110-115^{\circ} \mathrm{C}$ by weight at $4 \%$ increment rate.

2.1. Collection of Materials. In this research, a soil sample was collected from the Warsak road area situated in the northeast of Peshawar, Pakistan. To ensure satisfactory results, the sample was collected at 1 meter depth below the ground surface in airtight bags to minimize the natural moisture loss. This soil sample then was placed in an oven for drying to measure the natural moistures contents at $105^{\circ} \mathrm{C}$ for a 24-hour time interval. After the sieve analysis test, sieve \# 40 down material was stored for testing. Eighty (80) kilograms of two samples were separated for testing the stabilization by UMO and bitumen independently. UMO was collected from a local auto workshop. Bitumen (60 grade) was taken from the National Highway Authority (NHA) construction material laboratory. In this paper, authors restrict their research to $0 \%, 4 \%, 8 \%, 12 \%, 16 \%$, and $20 \%$ for 


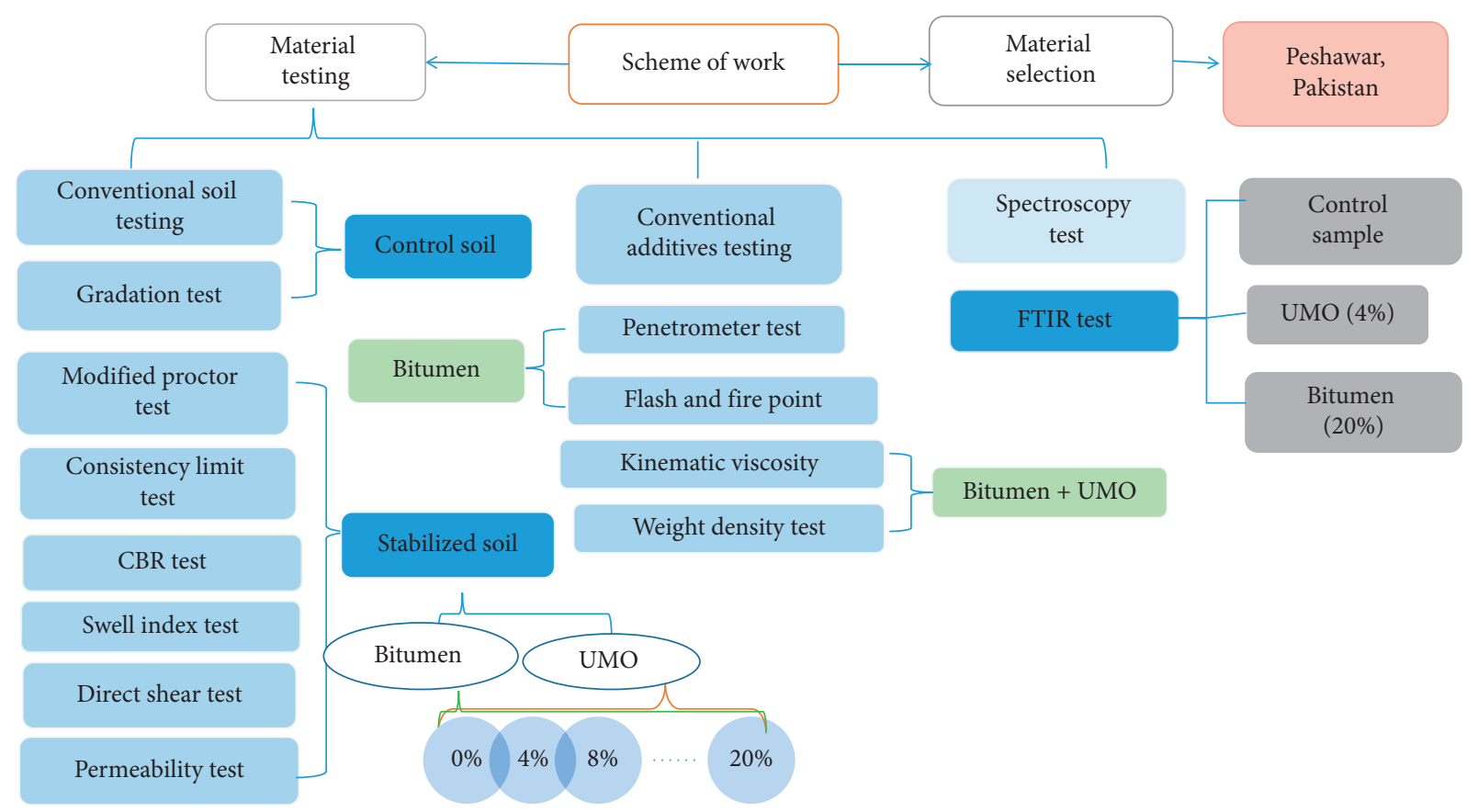

FIgURE 1: Work scheme flow chart.

both UMO and bitumen as soil stabilization independently. The unified soil classification system' (USCS') soil classification Chart Method D-2487 found that testing soil is inorganic clay of low plasticity or lean clay (CL) in nature.

\subsection{Preparation of Samples. Oven-dried samples were used} for each investigation, at a $4 \%$ increment of UMO and bitumen independently. Bitumen was added after heating it up to $140^{\circ} \mathrm{C}$ so that it can be poured and mixed easily without any hard lumps or air contents. Mixing was carefully done using spades until uniformity of color was perceived at $110-115^{\circ} \mathrm{C}$. Mixing in the case of UMO was easy as oil is less viscous as compared to bitumen even if heated. The sticking property of bitumen with soil particles makes flocculants in the soil sample.

2.3. Laboratory Tests. This research study was supported by various laboratory tests.

The physical properties of both UMO and bitumen were investigated and listed in Table 1. For this purpose, unit mass density, viscosity, flash, and fire points were calculated. The bitumen penetrometer test (ASTM D-5), the flash and fire point test (ASTM D-92), the weight density test (ASTM D-4052), and kinematic viscosity tests for oil (ASTM D-445) and for bitumen (ASTM D-2170) were performed. Table 2 summarizes the corresponding physical and chemical properties of the local soil sample.

Table 3 describes the overall performed testing summary on the soil sample stabilized with UMO and bitumen at a $4 \%$ increment rate. Tests such as the specific gravity test (ASTM D854-00), the particle size distribution test (ASTM D-422), Atterberg's limit test (ASTM D-4318), the modified proctor test (ASTM D-1557), the CBR test (ASTM D-1883-99), the direct shear test (ASTM D-3080), and the falling head permeability test (ASTM D-5084) were performed. Along with these basic geotechnical investigation tests, some microscopic analysis was also performed to visualize the basic internal changes due to the two types of additives.

\section{Results and Discussion}

3.1. Particle Size Distribution Test. Oven-dried weighed sample is poured on the sieve column with largest opening at the top ( $2 "$ sieve) to lower sieves with smaller openings (\#200 sieve) having a pan at the base. It was mechanically shaken for 12 minutes using mechanical shakers. After shaking, material received by each sieve was weighed with the digital balance having up to 0.1 gram sensitivity. Weight retained on every sieve is divided by total sample weight to get the percentage value of each sieve. To get a specific size range, each passing percentage value was analyzed and drawn as shown in Figure 2.

3.2. Compaction Test. The oven-dried soil sample was investigated to check the effects of UMO and bitumen on MDD and OMC, as presented in Figures 3 and 4. After each soil sample was divided into different suitable quantities, water was added in the probable OMC range. After three or four trials, we obtained the required OMC value. While calculating MDD and OMC, Figures 3 and 4 show that MDD increases by increasing bitumen up to $20 \%$. In the case of UMO, MDD increases up to $4 \%$ by $1.94 \%$, and thereafter inversely decreases. Normally, dry density decreases when increasing the rate of used motor oil [10, 27]. UMO shows this trend up to $4 \%$. On further addition of used oil above $4 \%$, the clusters of soil particles lose their cohesion due to a higher oil absorption rate causing reduction of soil unit 
TABLe 1: Properties of petroleum's additives.

\begin{tabular}{lccccccc}
\hline Material & Color & $\begin{array}{c}\text { Penetration at } \\
25^{\circ} \mathrm{C}(0.01 \mathrm{~mm})\end{array}$ & $\begin{array}{c}\text { Flash and fire } \\
\text { point }\left({ }^{\circ} \mathrm{C}\right)\end{array}$ & $\begin{array}{c}\text { Softening } \\
\text { point }\left({ }^{\circ} \mathrm{C}\right)\end{array}$ & $\begin{array}{c}\text { Kinematic viscosity } \\
\left(\mathrm{cst} \text { at } 100^{\circ} \mathrm{C}\right)\end{array}$ & $\begin{array}{c}\text { Weight density } \\
\left(\mathrm{kN} / \mathrm{m}^{3}\right)\end{array}$ & $\begin{array}{c}\text { Ductility } \\
(\mathrm{cm})\end{array}$ \\
\hline UMO & Bluish black & - & 161,167 & - & 8.19 & 8.7 & - \\
Bitumen & Shining black & 64 & 243,259 & 44 & 341 & 8.31 & 87 \\
\hline
\end{tabular}

TABLe 2: Physical and chemical characteristics of local soil sample.

\begin{tabular}{|c|c|c|c|c|c|c|c|c|c|c|c|c|}
\hline \multirow{2}{*}{ Soil type } & \multirow{2}{*}{ Color } & \multirow{2}{*}{ Density $\left(\mathrm{g} / \mathrm{cm}^{3}\right)$} & \multirow{2}{*}{ Unit weight $\left(\mathrm{kN} / \mathrm{m}^{3}\right)$} & \multicolumn{6}{|c|}{ Chemical analysis (\%) } & \multicolumn{3}{|c|}{ Composition (\%) } \\
\hline & & & & $\mathrm{Ca}$ & $\mathrm{O}$ & $\mathrm{C}$ & $\mathrm{Si}$ & $\mathrm{Al}$ & Others & Sand & Silt & Clay \\
\hline $\mathrm{CL}$ & Yellowish brown & 2.06 & 20.20 & 1.234 & 22 & 3.67 & 34 & 18 & 20.39 & 22 & 30 & 48 \\
\hline
\end{tabular}

TABLE 3: Laboratory investigation of UMO and bitumen-stabilized soil.

\begin{tabular}{|c|c|c|c|c|c|c|c|c|c|c|}
\hline & $\%$ & $\begin{array}{c}\mathrm{MDD} \\
\mathrm{gm} / \mathrm{cm}^{3}\end{array}$ & $\begin{array}{c}\text { OMC } \\
\%\end{array}$ & $\begin{array}{c}\text { CBR } \\
\%\end{array}$ & $\begin{array}{l}\text { “C” } \\
\mathrm{kPa}\end{array}$ & $\begin{array}{c}\Phi^{\circ} \\
\text { degree }\end{array}$ & $\begin{array}{c}\mathrm{LL} \\
\%\end{array}$ & $\begin{array}{c}\mathrm{PL} \\
\%\end{array}$ & $\begin{array}{l}\text { PI } \\
\%\end{array}$ & “ $k "$ \\
\hline \multirow{6}{*}{ Used motor oil } & 0 & 2.06 & 12.5 & 10.8 & 38 & 17 & 47.4 & 27.6 & 19.8 & $5.282 \times 10^{-6}$ \\
\hline & 4 & 2.1 & 12.1 & 10 & 33 & 18 & 45.9 & 29.1 & 16.8 & $5.202 \times 10^{-6}$ \\
\hline & 8 & 2.01 & 12 & 6.9 & 32.1 & 18.8 & 43.2 & 29.3 & 13.9 & $5.009 \times 10^{-6}$ \\
\hline & 12 & 1.93 & 10.3 & 0 & 30 & 20 & 42.7 & 30.4 & 12.3 & $5.017 \times 10^{-6}$ \\
\hline & 16 & 1.87 & 8.8 & 0 & 26 & 21 & 40.6 & 31.3 & 9.3 & $5.152 \times 10^{-6}$ \\
\hline & 20 & 1.84 & 7.6 & 0 & 22 & 23 & 38.2 & 32.1 & 6.1 & $5.209 \times 10^{-6}$ \\
\hline \multirow{6}{*}{ Bitumen } & 0 & 2.06 & 12.5 & 10.8 & 38 & 17 & 47.4 & 27.9 & 19.7 & $5.282 \times 10^{-6}$ \\
\hline & 4 & 2.13 & 13.7 & 12.7 & 38.7 & 16 & 42.3 & 23.89 & 18.5 & $5.162 \times 10^{-6}$ \\
\hline & 8 & 2.23 & 13.4 & 14.4 & 39.4 & 14.7 & 39.7 & 21.6 & 18.1 & $4.990 \times 10^{-6}$ \\
\hline & 12 & 2.29 & 13.21 & 15 & 41 & 13.8 & 35.5 & 18.5 & 17 & $4.292 \times 10^{-6}$ \\
\hline & 16 & 2.37 & 12.6 & 18 & 45 & 13 & 33.6 & 18 & 15.6 & $3.702 \times 10^{-6}$ \\
\hline & 20 & 2.42 & 9.9 & 21 & 51 & 6 & 31.2 & 16.6 & 14.6 & $3.382 \times 10^{-6}$ \\
\hline
\end{tabular}

MDD, maximum dry density, $C$, cohesion, OMC, optimum moisture content, " $\phi$," angle of internal friction, PL, plastic limit, CBR, California bearing ratio, " $k$," coefficient of permeability, LL, liquid limit, and PI, plasticity index.

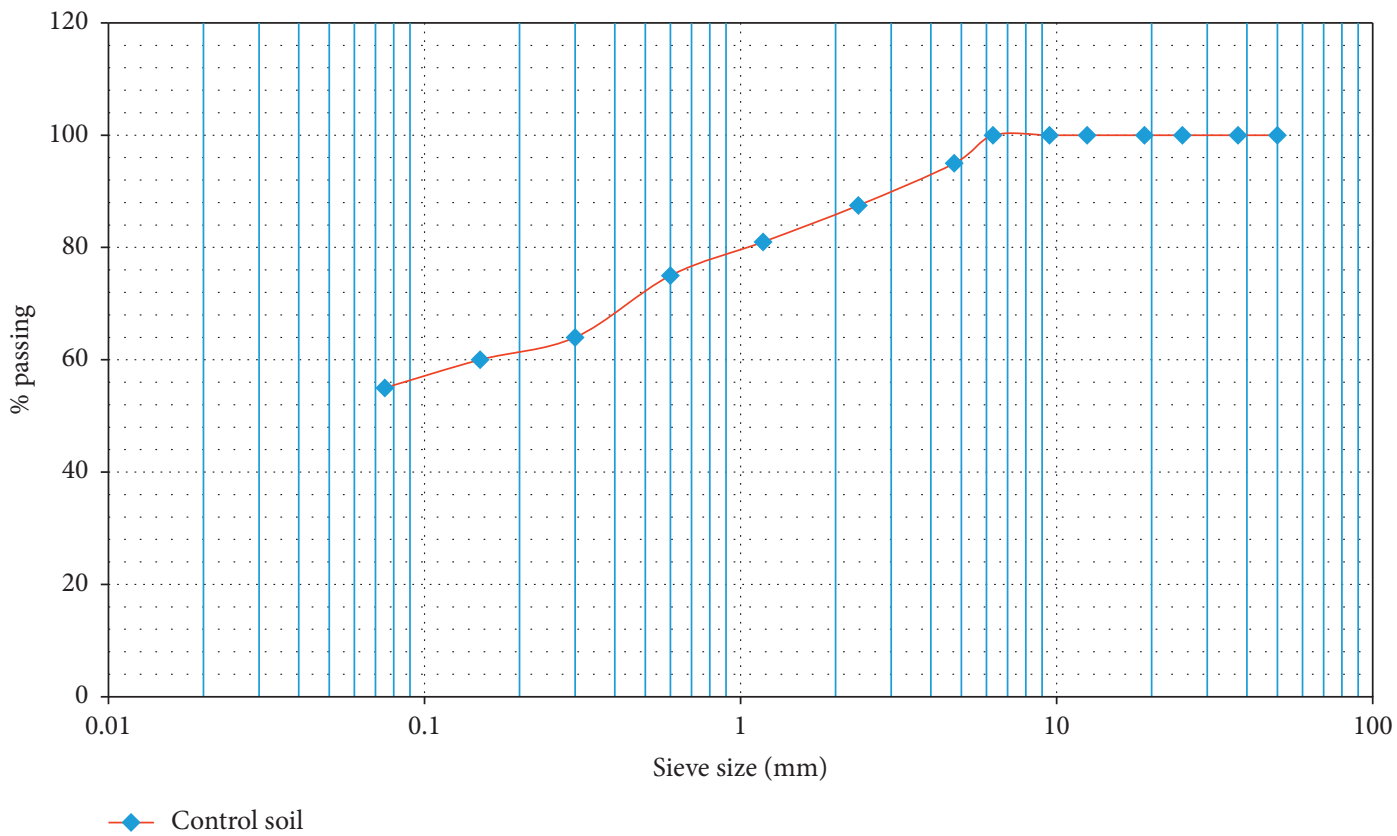

Figure 2: Particle size distribution. 


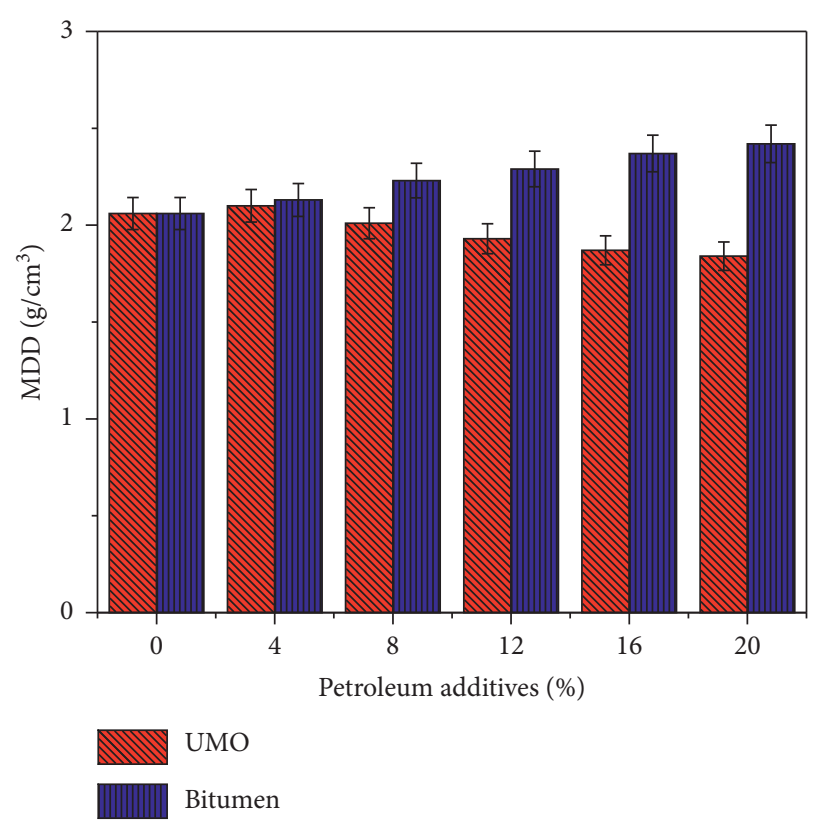

FIGURE 3: Variation of maximum dry density (MDD) with bitumen and UMO content.
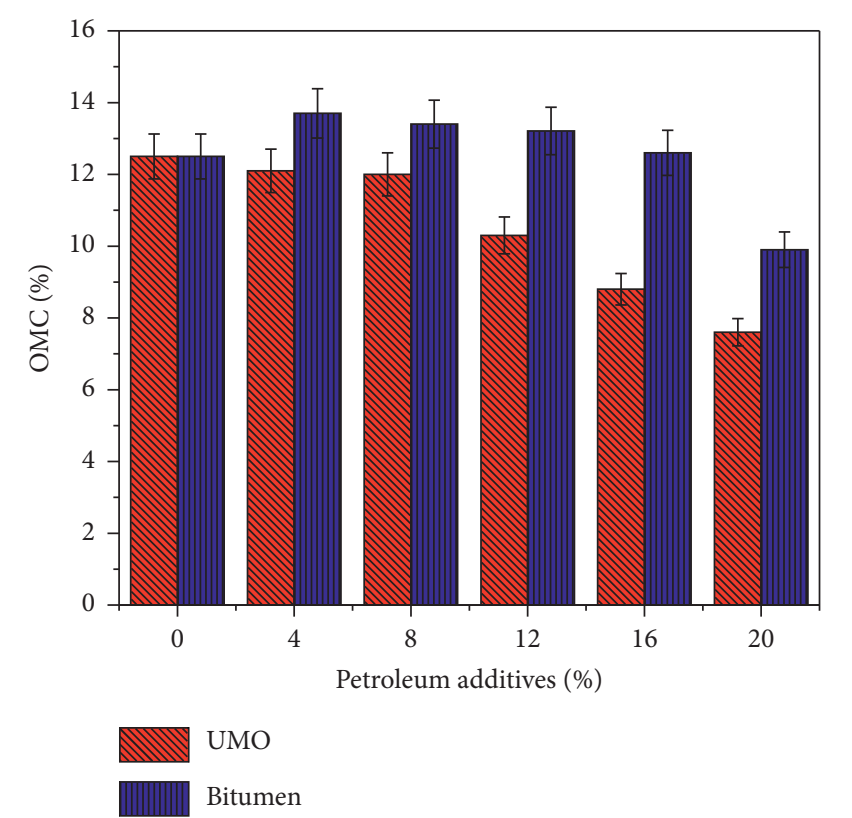

FIgURE 4: Variation of optimum moisture content (OMC) with bitumen and UMO content.

density. On the other hand, bitumen as a stabilizer in soil shows an ascending approach and increases the MDD as high as $17.47 \%$. Because bitumen holds the soil particles in clusters which increases the compressibility of soil, bitumen increases the soil density. Further, bitumen itself is cohesive in nature at low temperature; hence, it causes the particles of the soil to cohere, leading to an increase in the effective cohesion and maximum density.

Figure 4 shows the OMC value, and it reveals that that OMC in bitumen-stabilized soil initially increases up to $4 \%$ and thereafter decreases. Bitumen increased OMC in the first $4 \%$ increment because of bunches formation in the soil, which increase the absorbing characteristic of soil. On further addition of UMO in soil, OMC continuously decreases for 39\%. According to Al-Homoud et al., cutback bitumen decreases MDD and increases OMC up to 7\% [28]. The declination in OMC is due to the repelling property of oil and bitumen. While UMO plays a part in decreasing the moisture content, UMO has itself low viscosity, which acts like water, so extra water than OMC will make the water film thicker, in consequence of which binding of particles does not take place that cause reduction in MDD [29]. Ojuri et al. studied the effect of UMO in soil stabilization and found that MDD and OMC decrease when increasing UMO contents [30].

3.3. CBR Test. Figure 5 shows the effect of UMO and the bitumen effect on soaked CBR. It is clear from the figure that the soaked CBR increased by increasing bitumen rate and decreased with increasing UMO. Zumrawi et al. worked on expansive soil stabilization with bitumen and fly ash. Their results are quite in line with our experimental results $[30,31]$. Andavan et al. illustrated that bitumen emulsion brings considerable improvement in the CBR value if properly mixed [32]. The similar result was found by carrying a number of tests on bitumen-stabilized expansive soil by Krishnaiah et al. [33]. On the other hand, as the swell percentage increases with used motor oil, it shows no resistance to standard piston penetration that gives zero CBR above $8 \%$ oil addition [27].

3.4. Swell Percentage Index Test. Prior to the soaking CBR test, percentage swell was measured for various UMO and bitumen contents from $0 \%$ to $20 \%$ at a $4 \%$ increment interval rate. Figure 6 shows that heated bitumen causes a reduction in swell percentage rate, while UMO increases in the swell index. Singh et al. reported a significant increase in swell percentage in CL soil with UMO that ultimately increases differential settlement [27].

Bitumen imparts cohesive property to the soil and does not allow water to enter; hence, the swell index decreases [32]. Al-Homoud et al. found a significant reduction in the swell index by treating soil with bitumen [28]. On the other hand, the UMO makes a thin film around the soil individual particle or sum of particles and makes it even coarser. Thus, when soil is stabilized with UMO, moisture and oil contents stored in the void spaces developed internal stresses that cause free void spaces and leads to decrease in the cohesion and increase in the swell percentage.

3.5. Direct Shear Test. The reduction in the shear strength of soil sample due to water can be minimized by introducing a waterproofing material such as bitumen in the soil sample. The best way to do this is by providing a layer coating of a waterproofing agent [34].

Figures 7 and 8 show the direct shear parameters that are cohesive (attractive force between soil particles) and the 


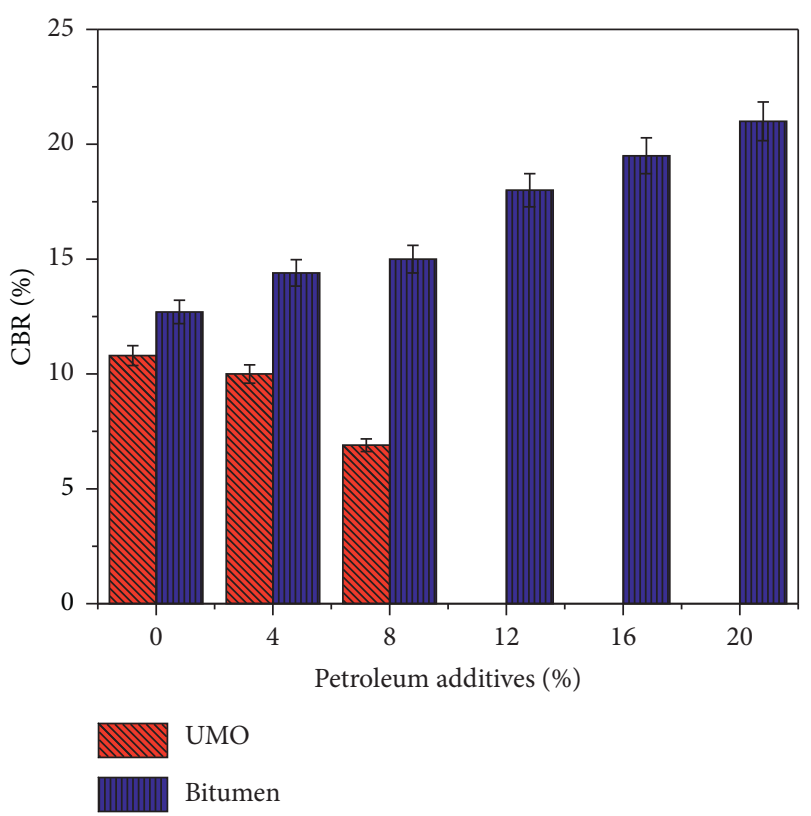

FIGURE 5: Variation of California bearing ratio (CBR) with bitumen and UMO contents.

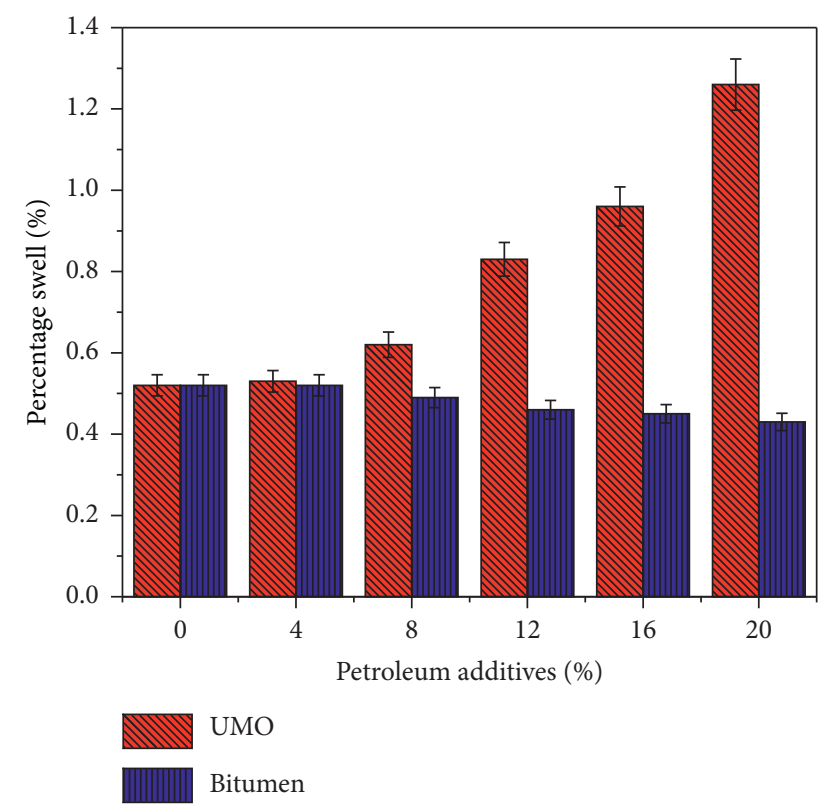

FIgURE 6: Variation of percentage swell with bitumen and UMO contents.

angle of internal friction $\phi$ (resistance to shearing movement) based on Coulomb's shear strength theory. Results show that cohesion increases by increasing the rate of bitumen. The angle of internal fraction increases to a peak value for UMO concentration of $20 \%$. While it gives the lowest value at $20 \%$ bitumen concentration as shown in Figure 8.

Conversely, cohesion decreases with increased rate of bitumen, which is obviously a sign of losing shear strength. There is less cohesion between the soil particles and the particles of oil; hence, UMO, the shear strength, decreases.

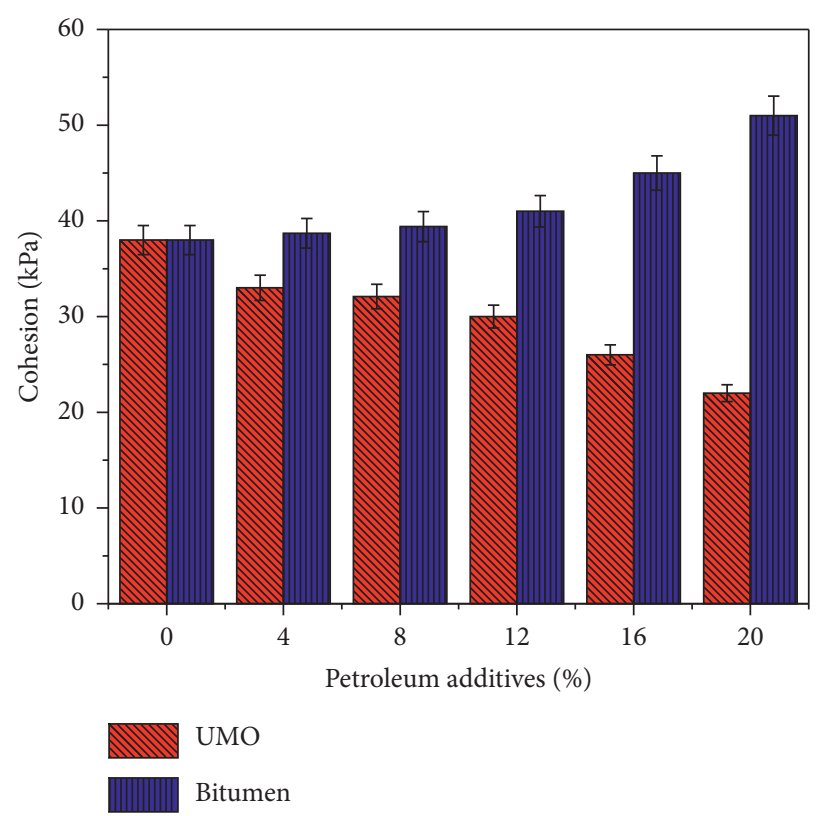

FIgURE 7: Variation of cohesion " $C$ " with bitumen and UMO contents.

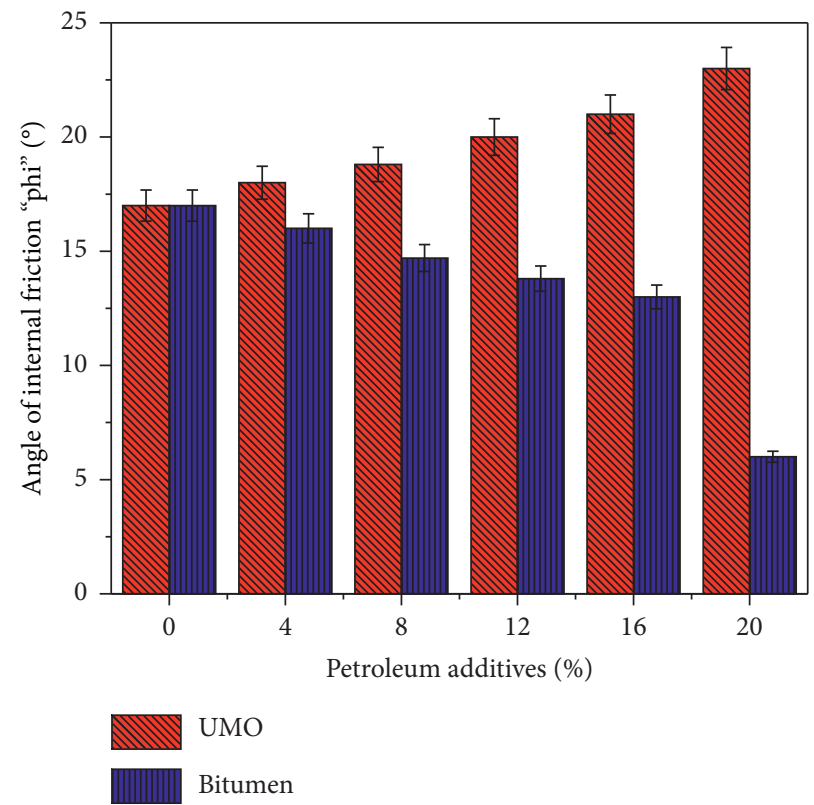

FIgURE 8: Variation of the angle of internal friction (ф) with bitumen and UMO contents.

Figure 8 shows the angle of internal friction "phi" that decreases in the case of bitumen, while it increases in the UMO case.

3.6. Atterberg's Limit Test. A higher variation in the case of consistency limits is observed in both bitumen and used motor oil used as a soil stabilizer. Figure 9 shows that both bitumen and used motor oil decrease the rate of liquid limit. The decrease in the liquid limit (both oil and bitumen case) and plastic limit (bitumen case only) is because of the 


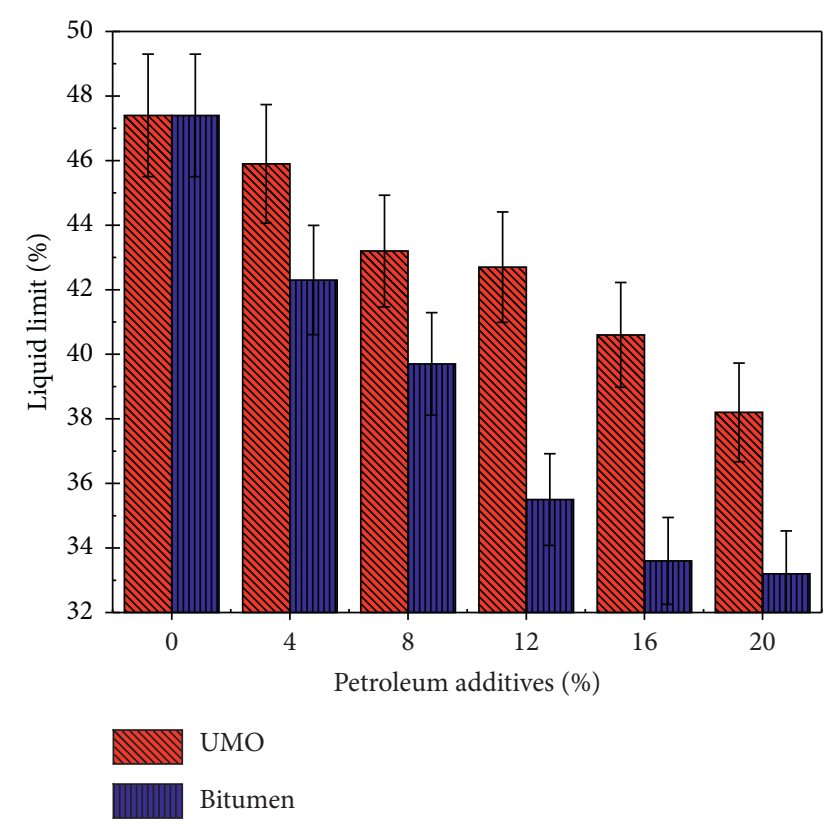

FIGURE 9: Variation of liquid limit with bitumen and UMO stabilization.

flocculation and agglomeration of the minerals present in the soil due to isomorphous substitution of cations at the surface of soil particles that resembles previous findings [35-37]. However, increases in the plastic limit with UMO might be due to the particle thickness due to the cation effect between soil particles and used oil (Figure 10). Salih et al. found that UMO not only increases the PL but also LL and PI [38]. Rasheed et al. reported that Atterberg's value of overconsolidated clay decreases by increasing UMO contents [11]. LL and PL decrease by increasing UMO contents $[19,27]$. Figure 11 shows that the plasticity index of the soil decreases while increasing both Bitumen and UMO.

3.7. Permeability Test. For safe operation of traffic and long life period, remote water and hinterland water which intercept the road embankment is an important element [39]. Figure 12 describes the coefficient of the permeability " $k$ " test, conducted on the used motor oil and bituminous stabilized soil. It is observed that up to $8 \%$ UMO addition causes a decrease in the permeability effect of the local soil and beyond great increases because of the coarser effect of the soil. It is observed that the coefficient of permeability " $k$ " fell by $5.83 \%$, but on further addition of UMO, the permeability increases up to $4.5 \%$ as the soil sample coarsens with the addition of UMO as a soil stabilizer.

The increasing rate of bitumen from $0 \%$ to $20 \%$ reduces the coefficient of permeability to go as low as $40 \%$ and thus minimizes the deleterious impact of percolated water. The reason is that the strong adhesive force of bitumen prevented the water from percolating through the voids by blocking the pathways. Venkatesh demonstrated that bitumen causes reduction in the permeability of soil [40]. Resistance to water or impermeability is mostly estimated by the value of water

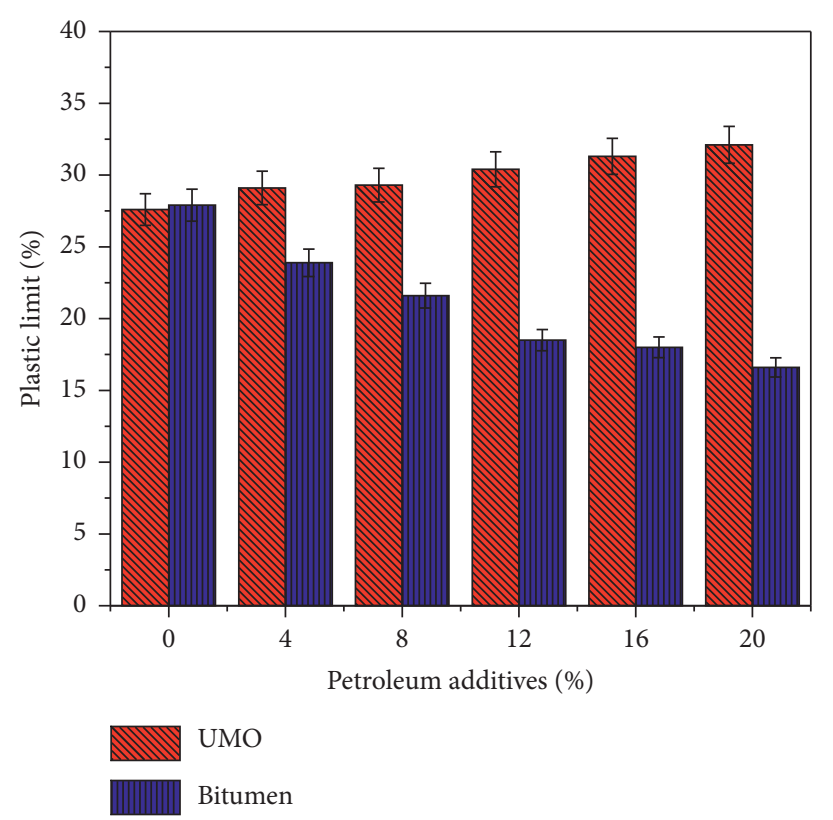

FIGURE 10: Variation of plastic limit with bitumen and UMO stabilization.

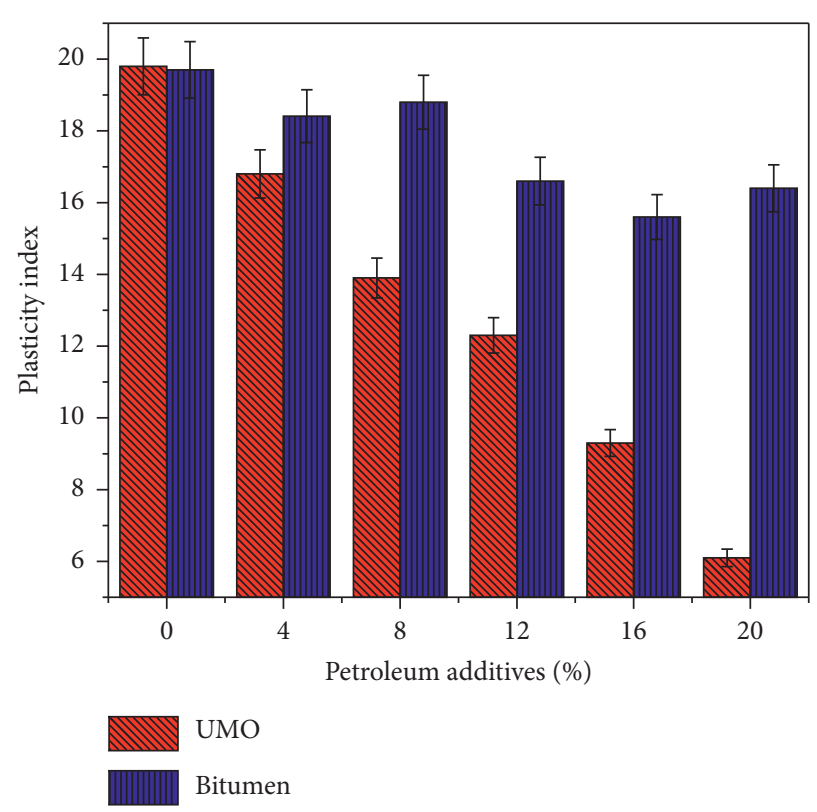

FIGURE 11: Variation of plasticity index with bitumen and UMO stabilization.

absorption or penetration. According to Fang, if bitumen in liquid form is mixed with soil up to $5-6 \%$, irrespective of the type of soil, the absorption will be less than $2 \%$ [41].

3.8. FTIR Test. Functional groups and molecular structures have different absorptions rate of infrared radiation. Therefore, chemical compositions of control and modified soil samples were identified through the analysis of infrared absorption spectrum. Spectrometry was performed having a wavenumber $500-4000 \mathrm{~cm}^{-1}$ with 0.1 accuracy wavelength. 

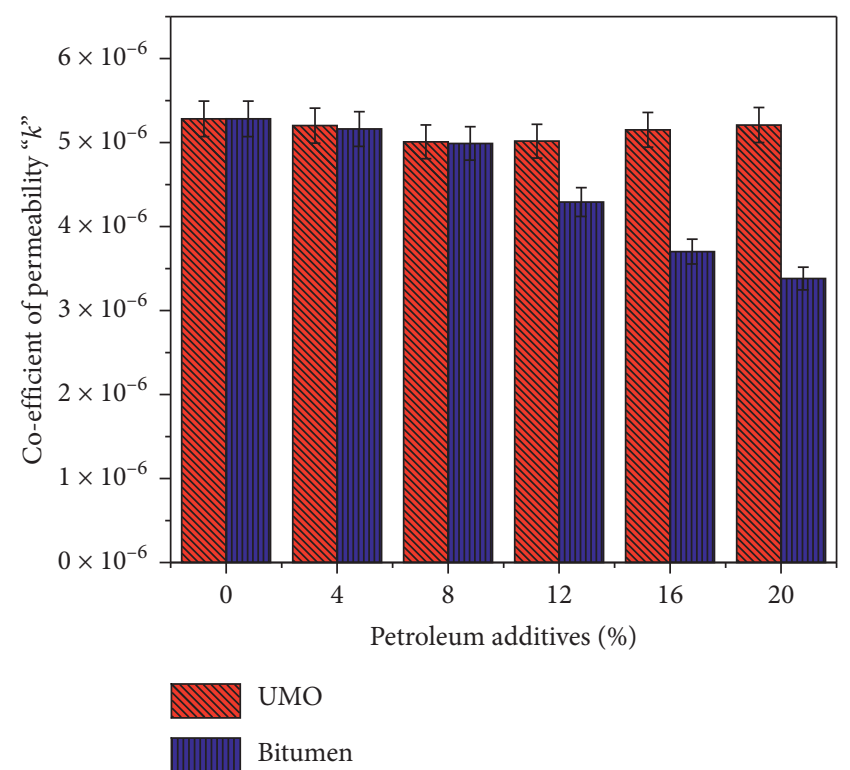

FIGURE 12: Relationship between coefficient of permeability " $k$ " with bitumen and UMO contents.

FTIR tests were performed for the soil sample at which maximum dry density (strength) was obtained in the stabilization process. As seen in Figure 3, UMO gives maximum dry density at $4 \%$, while bitumen does so at $20 \%$. Through FTIR tests, we compared the changing spectrum of $4 \%$ UMO stabilized soil sample and 20\% bitumen-stabilized soil sample to that of control soil sample.

FTIR results for control soil and stabilized soil with UMO and bitumen were observed with tremendous changes in the peaks values. The difference in transmission or absorbance usually arises due to difference in concentration, as described by Lambert's law [42], which states that absorption depends on path length, concentration, and strength of absorbance band. In Figure 13, different peaks can be seen: a very broad peak at $3600 \mathrm{~cm}^{-1}$ shows that the $\mathrm{OH}$ group is present, a very small peak at $3000 \mathrm{~cm}^{-1}$ shows that the $\mathrm{CH}$ group is present at lowest intensity, the peak at $2500 \mathrm{~cm}^{-1}$ shows the SH group, the peak at $1500 \mathrm{~cm}^{-1}$ shows the N-O group, and a very sharp and intense peak at $1000 \mathrm{~cm}^{-1}$ represents $\mathrm{C}-\mathrm{O}$. So, it is clear from Figure 13 that natural soil contained compounds having $\mathrm{C}-\mathrm{O}, \mathrm{NO}, \mathrm{SH}$, and $\mathrm{CH}$ functional groups, but the concentration of S-H and N-O containing compounds are low. In Figure 13, the position of the peak is identical but the intensity of peaks varies, peaks at $3600 \mathrm{~cm}^{-1}$ become broad and increase in length, which shows that more absorbance occurs in this case due to increase in the concentration of compounds, while the intensity of peaks at $3000 \mathrm{~cm}^{-1}$ and $1500 \mathrm{~cm}^{-1}$ increases, which is an indication of the concentration of $\mathrm{CH}$ and $\mathrm{NO}$ containing compounds increment after addition of used oil into the soil. Similarly, in Figure 13, the intensity of peaks increase, and peaks at $3600 \mathrm{~cm}^{-1}, 3000 \mathrm{~cm}^{-1}$, and $1500 \mathrm{~cm}^{-1}$ become more intense, which show the concentration of $\mathrm{CH}$, and $\mathrm{NO}$ containing compounds increased after the addition of bitumen to the soil. The peaks at $2500 \mathrm{~cm}^{-1}$ and $1000 \mathrm{~cm}^{-1}$ did not show more increase in intensity, which confirm that

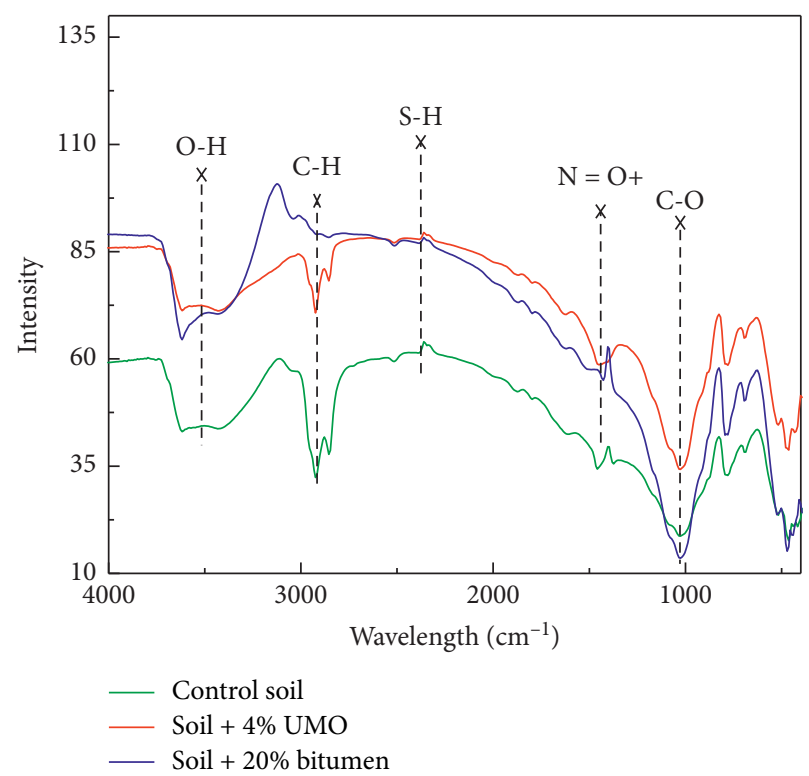

FIGURE 13: FTIR wavelength intensity spectra.

when bitumen is added to soil, the amount of $\mathrm{SH}$ and $\mathrm{C}-\mathrm{O}$ containing compounds are not increased. Figure 12 shows that oil and bitumen are organic compounds, and they increase the intensity of soil by leaving the hydrocarbons and sulphur content in the soil mix, which impart cementitious properties to the soil mix. UMO contains a lesser amount of hydrocarbons but more carbonyl groups from ketones or acids, while bitumen contains a greater number of hydrocarbons. A large number of hydrocarbons makes the soil hard and gives antiwater characteristic to the soil, decreases the ability to absorb water, and makes it waterproof. So far, from the FTIR result, it is confirmed that bituminous is more effective instead of waste oil in soil stabilization.

\section{Conclusions}

In this research work, the stabilizing effect of UMO and bitumen was studied by mixing it with a local soil sample to evaluate its geotechnical properties and specifying the application of that soil in embankment layers. Mechanical and chemical laboratory tests were performed, and graphical tools were used to reach the following conclusions:

(1) The local roads and district highways condition can be improved by using the waste motor oil up to $4 \%$ effectively. This research work illustrates that $4 \%$ of $\mathrm{UMO}$ is the effective percentage for soil stabilization. Above $4 \%$, it has an inverse effect on soil stabilization.

(2) Bitumen as a stabilizer agent was proved to be more effective than UMO. Native soil can be stabilized up to $20 \%$ bitumen and used in the embankment layers.

(3) CBR results show that bitumen is a better stabilizer to give strength to the soil as compared to UMO.

(4) Swell percentage in the case of UMO shows a tremendous rise that reduces the soaked CBR to $0 \%$. 
(5) Bitumen reduces the permeability of the soil more effectively as compared to motor oil.

(6) The liquid limit tends to decrease with the addition of bitumen and UMO. Similarly, plasticity decreases with bitumen increasing. It initially increases and then decreases with UMO increasing.

(7) The variation in graph peaks from the FTIR test indicates that bitumen impart more cementing characteristic than UMO because of more hydrocarbons, which give higher concentration.

\section{Data Availability}

The data used to support this study are available from the corresponding author upon request.

\section{Conflicts of Interest}

The authors declare that they have no conflicts of interest.

\section{Authors' Contributions}

Kamran Iqbal designed and executed the laboratory test plan, developed the methodology and empirical data, contributed to conceptualization of the research, and drafted the manuscript. Prof. Dr. Xu Chengshun provided guidance and suggestions to improve this study. Prof. Dr. Hassan Nazir analyzed the test results and checked the validity of the data. Prof. Dr. Muhammad Alam contributed to the review process, enhanced the methodology, and helped in technical writing. Asst. Prof. Dr. Asim Farooq contributed to conceptualization and presented the discussion along with illustrative examples in the manuscript. Prof. Dr. Edward J. Williams, being a native speaker and experienced writer, improved and tightened the English writing of the manuscript.

\section{Acknowledgments}

This research was undertaken with the support of Prof. Dr. $\mathrm{Xu}$ Cheng-shun, Beijing University of Technology, Beijing, China. The authors would like to thank Dr. Asim Farooq and Prof. Edward J. Williams for their valuable guidance and motivation during the entire research work.

\section{References}

[1] J. Mitchell and J. Younger, "Abnormalities in hydraulic flow through fine-grained soils," in Permeability and Capillarity of Soils, ASTM International, West Conshohocken, PA, USA, 1967.

[2] T. E. Kowalaski and D. W. Starry, "Characterization and improvement of soils and materials session," in Proceedings of the Annual Conference of the Transportation Association of Canada, Saskatoon, Canada, October 2007.

[3] A. Rashid, X. Chen, K. Harijan, Z. A. Dhakan, and M. Ammar, "A comparative study of recycling of used engine oil using extraction by composite solvent, single solvent and acid treatment methods," ISRN Chemical Engineering, vol. 2013, Article ID 952589, 5 pages, 2013.
[4] F. A. Carey and R. M. Giuliano, Organic Chemistry, McGrawHill Education, New York, NY, USA, 2017.

[5] K. Ramadass, M. Megharaj, K. Venkateswarlu, and R. Naidu, "Ecological implications of motor oil pollution: earthworm survival and soil health," Soil Biology and Biochemistry, vol. 85, pp. 72-81, 2015.

[6] M. Gyasi, Levels of Contaminants in Used Motor Oil and Their Potential Effect on the Environment (Doctoral Dissertation), KNUSTSpace, Kumasi, Ghana, 2016.

[7] P. Falcone and E. Imbert, "Social life cycle approach as a tool for promoting the market uptake of bio-based products from a consumer perspective," Sustainability, vol. 10, no. 4, p. 1031, 2018.

[8] E. Evgin and B. M. Das, "Mechanical behavior of an oil contaminated sand," in Proceedings of the Mediterranean Conference on Environmental Geotechnology, pp. 101-108, Cesme, Turkey, May 1992.

[9] M. Khamehchiyan, A. H. Charkhabi, and M. Tajik, "Effects of crude oil contamination on geotechnical properties of clayey and sandy soils," Engineering Geology, vol. 89, no. 3-4, pp. 220-229, 2007.

[10] E. C. Ukpong and I. C. Umoh, "Effect of crude oil spillage on geotechnical properties of lateritic soil in Okoroete, Eastern Obololo," International Journal of Engineering and Applied Sciences, vol. 7, no. 1, pp. 12-24, 2015.

[11] Z. N. Rasheed, F. R. Ahmed, and H. M. Jassim, "Effect of crude oil products on the geotechnical properties of soil," WIT Transaction on Ecology and The Environment, vol. 186, pp. 353-362, 2014.

[12] A. K. Nazir, "Effect of motor oil contamination on geotechnical properties of over consolidated clay," Alexandria Engineering Journal, vol. 50, no. 4, pp. 331-335, 2011.

[13] J. M. Bhatnagar, N. L. Goswami, and S. M. Singh, "Stabilized soil in brickmaking," Batiment International, Building Research and Practice, vol. 16, no. 3, pp. 177-181, 1988.

[14] D. R. Vazquez, "Environmental impact of used motor oil," The Science of the Total Environment, vol. 79, no. 1, pp. 1-23, 1989.

[15] P. G. Nicholson, "Admixture soil improvement," Soil Improvement and Ground Modification Methods, pp. 231-288, Elsevier, Amsterdam, Netherlands, 2015.

[16] A. Naudts and S. Hooey, "Hot bitumen grouting: the antidote for catastrophic inflows," in Grouting and Ground Treatment, pp. 1293-1304, ASCE Library, New Orleans, LA, USA, 2003.

[17] E. Schönian, The Shell Bitumen Hydraulic Engineering Handbook, Shell Bitumen, The Hague, Netherlands, 1999.

[18] K. Onyelowe, D. Bui Van, C. Igboayaka, F. Orji, and H. Ugwuanyi, "Rheology of mechanical properties of soft soil and stabilization protocols in the developing countriesNigeria," Materials Science for Energy Technologies, vol. 2, no. 1, pp. 8-14, 2019.

[19] H. J. Pincos, N. J. Meegoda, and P. Ratnaweera, "Treatment of oil-contaminated soils for identification and classification," Geotechnical Testing Journal, vol. 18, no. 1, pp. 41-49, 1995.

[20] A. M. Nasr, "Behavior of strip footing on fiber-reinforced cemented sand adjacent to sheet pile wall," Geotextiles and Geomembranes, vol. 42, no. 6, pp. 599-610, 2014.

[21] M. F. Conway, "Bench-scale evaluation of asphalt emulsion stabilization of contaminated soils," Journal of Soil Contamination, vol. 2, no. 2, pp. 157-165, 1993.

[22] V. K. Pala, "An experimental investigation on use of bitumen emulsion in the construction of gravel road," American Journal of Educational Research and Reviews, vol. 4, 2019.

[23] Y. Huan, K. Siripun, P. Jitsangiam, and H. Nikraz, "A preliminary study on foamed bitumen stabilisation for Western 
Australian pavements," Scientific Research and Essays, vol. 5, no. 23, pp. 3687-3700, 2010.

[24] D. K. Paul and C. T. Gnanendran, "Characterization of lightly stabilized granular base materials using monotonic and cyclic load flexural testing," Journal of Materials in Civil Engineering, vol. 28, no. 1, Article ID 04015074, 2015.

[25] D. Jones, A. Rahim, S. Saadeh, and J. T. Harvey, Guidelines for the Stabilization of Subgrade Soils in California, University of California, Oakland, CA, USA, 2012.

[26] K. R. Arora, Soil Mechanics and The Foundation Engineering Books, Standard Publishers, Delhi, India, 1987.

[27] S. K. Singh, R. K. Srivastava, and S. John, "Studies on soil contamination due to used motor oil and its remediation," Canadian Geotechnical Journal, vol. 46, no. 9, pp. 1077-1083, 2009.

[28] A. S. Al-Homoud, T. Khedaywi, and A. M. Al-Ajlouni, "Studies on the control of swell and collapse potential of selected Jordanian soils using asphalt stabilization," Soils and Foundations, vol. 35, no. 2, pp. 15-23, 1995.

[29] A. Patel, Geotechnical Investigations and Improvement of Ground Conditions, Woodhead Publishing, Sawston, UK, 2019.

[30] O. O. Ojuri and O. O. Ogundipe, "Modeling used engine oil impact on the compaction and strength characteristics of a lateritic soil," Electronic Journal of Geotechnical Engineering, vol. 17, p. 3491, 2012.

[31] M. Zumrawi and M. Awad, "Effect of bitumen and fly ash on expansive soil properties," Journal of Scientific and Engineering Research, vol. 2017, no. 49, pp. 228-237, 2017.

[32] S. Andavan and B. M. Kumar, "Case study on soil stabilization by using bitumen emulsions-a review," Materials Today: Proceedings, vol. 22, pp. 1200-1202, 2020.

[33] D. R. V. Krishnaiah, P. Dayakar, K. Venkatraman, and B. BIST, "Effect of bituminous admixtures on CBR strength of expensive soil," International Journal of Pure and Applied Mathematics, vol. 119, no. 12, 2018.

[34] H. F. Winterkorn, "Granulometric and volumetric factors in bituminous soil stabilization," in Proceedings of Highway Research Board, vol. 36, pp. 773-782, Washington, DC, USA, 1957.

[35] S. I. Adedokun, "Valorization of spent engine oil contaminated lateritic soil with high calcium waste wood ash," Journal of Engineering Research, vol. 7, no. 1, 2019.

[36] A. B. Salahudeen and J. Ochepo, "Effect of bagasse ash on some engineering properties of lateritic soil," Jordan Journal of Civil Engineering, vol. 9, no. 4, pp. 468-476, 2015.

[37] T. Ramzi, A. Amer, A. Ali, and A. Hilia, "Use of cement kiln dust in soil stabilization," Engineering Journal of the University of Qatar, vol. 14, pp. 61-76, 2001.

[38] N. B. Salih, T. A. Abdalla, and S. A. Ali, "Effect of waste engine oil contamination on the geotechnical properties of cohesive soils in sulaimani city, Iraq," Association of Arab Universities Journal of Engineering Sciences, vol. 27, no. 1, pp. 11-18, 2020.

[39] A. R. Dawson, "Water in road structures," in Geotechnical, Geological and Earthquake Engineering, Springer, Berlin, Germany, 2009.

[40] S. Venkatesh, "Silty soil stabilization using bituminous emulsion," International Journal and Magazine of Engineering, Technology, Management and Research, vol. 4, no. 10, 2017.

[41] H.-Y. Fang, Foundation Engineering Handbook, p. 923, Kluwer Academic Publishers, Boston, MA, USA, 1991.

[42] D. F. Swinehart, “The beer-lambert law," Journal of Chemical Education, vol. 39, no. 7, p. 333, 1962. 